\title{
Kinerja Karyawan Industri Manufaktur Perkayuan Kaitannya dengan Kelelahan Kerja (Burnout) dan Disiplin Kerja.
}

\author{
M. T. S. Gunawan ${ }^{1}$, Sumiyati, \& Masharyono \\ Universitas Pendidikan Indonesia \\ muhamadtaufuk@student.upi.edu
}

\begin{abstract}
Objective of this research is to determine the effect of burnout and work discipline on employee performance. This research was conducted in a span of less than one year, so the research design used was a crosssectional method. This study uses a descriptive and verification approach with explanatory survey methods. A total of 100 respondents were selected as samples using probability sampling. The research questionnaire is used as a research instrument to collect data from respondents, and the data analysis technique used is multiple linear regression. The findings of this research is work fatigue (burnout) and work discipline have a significant influence on employee performance. Differences found in objects and research methods, population and research samples, research periods, measurement tools and research results, and sources of theory from foreign journals and foreign books
\end{abstract}

\footnotetext{
ABSTRAK

Tujuan penelitian ini adalah untuk mengetahui pengaruh kelelahan kerja (burnout) dan disiplin kerja terhadap kinerja karyawan. Penelitian ini dilakukan pada rentang waktu kurang dari satu tahun, maka desain penelitian yang digunakan adalah cross-sectional method. Penelitian ini menggunakan pendekatan deskriptif dan verifikatif dengan metode explanatori survei. Sebanyak 100 responden dipilih sebagai sample menggunakan probabiliti sampling. Angket penelitian digunakan sebagai instrumen penelitian untuk mengumpulkan data dari responden, serta teknik analisis data yang digunakan adalah regresi linier berganda. Temuan dari penelitian ini adalah kelelahan kerja (burnout) dan disiplin kerja berpengaruh secara signifikan terhadap kinerja karyawan. Perbedaan ditemukan dalam objek dan metode penelitian, populasi dan sampel penelitian, periode penelitian, alat ukur dan hasil penelitian, serta sumber teori dari jurnal asing dan buku asing.
}

\section{PENDAHULUAN}

Globalisasi yang ditunjang dengan perkembangan peradaban manusia telah menjadikan dunia menjadi transparan tanpa mengenal batas-batas negara. Dengan perkembangan teknologi yang begitu

\section{ARTICLE INFO: Article history: Received 30 January 2017 Revised 31 January 2017 Accepted 31 January 2017 Available online 20 May 2017}

\section{Keywords:}

Employee Work

Performance.

Work Fatigue (Burnout).

Work Discipline

\section{Kata Kunci: \\ Disiplin Kerja: Kinerja \\ Karyawan, \\ Kelelahan Kerja(Burnout}

pesat, masyarakat dunia khususnya masyarakat Indonesia terus berubah sejalan dengan perkembangan teknologi, dari masyarakat pertanian ke masyarakat industri dan berlanjut ke masyarakat pasca industri yang serba teknologis. Sumber Daya Manusia 
(SDM) merupakan salah satu faktor kunci dalam persaingan global, yakni bagaimana menciptakan SDM yang berkualitas dan memiliki keterampilan serta berdaya saing tinggi dalam persaingan global yang selama ini kita abaikan. Globalisasi yang sudah pasti dihadapi oleh bangsa Indonesia menuntut adanya efisiensi dan daya saing dalam dunia usaha.

Kinerja karyawan yang baik akan menciptakan hasil kerja yang baik pula sehingga perusahaan melakukan berbagai cara agar kualitas kinerja karyawan mereka terus meningkat. Jika kinerja karyawan dalam suatu perusahaan mengalami penurunan maka akan berpengaruh terhadap produk yang dihasilkan akan mengalami penurunan kualitas sehingga secara tidak langsung merugikan perusahaan karena tujuan perusahaan akan sulit untuk tercapai dan bukan tidak mungkin perusahaan akan sulit bersaing dengan perusahaan pesaingnya.

Perusahaan akan berusaha dengan keras untuk mencapai tujuannya, dengan demikian karyawan dituntut untuk bekerja secara optimal, namun pada kenyataannya kualitas kinerja karyawan masih belum optimal.

Industri manufaktur di Indonesia khususnya di bidang perkayuan, barang dari kayu dan gabus (tidak termasuk furnitur) dan barang anyaman dari bambu, rotan dan sejenisnya merupakan barometer peningkatan perekonomian nasional dalam upaya meningkatkan devisa negara dari sektor kehutanan. Perkembangan industri manufaktur Indonesia secara umum berada dalam tren yang kurang begitu baik. Walaupun industri kayu dan furnitur saling berhubungan satu dengan yang lainnya, namun indeks produksi kayu jauh di bawah indeks produksi furnitur. Industri perkayuan, barang dari kayu, gabus dan rotan bergerak fluktuatif dengan kecenderungan bergerak dalam tren yang sedang menurun. (Sumber: situs resmi Badan Pusat Statistik Indonesia).

PT. Lestari Mahaputra Buana adalah salah satu perusahaan yang bergerak dibidang industri pengolahan kayu untuk dibuat menjadi berbagai macam alat tulis seperti pensil, penggaris, jangka dan yang lain sebagainya. Dari hasil penilaian kualitas kinerja karyawannya, PT. Lestari Mahaputra Buana mengalami penurunan. (Sumber: Bagian HRD PT. Lestari Mahaputra Buana).

Berbagai macam faktor yang mempengaruhi kinerja karyawan baik dari dalam maupun dari luar perusahaan, antara lain kurangnya kemampuan karyawan, ketidakdisiplinan karyawan, motivasi kerja karyawan yang rendah, kelelahan kerja (burnout) dan lain sebagainya. Salah satu faktor yang paling mempengaruhi rendahnya kinerja karyawan pada PT. Lestari Mahaputra Buana adalah tingginya angka kelelahan kerja (burnout) pada karyawan. (Sumber: Bagian HRD PT. Lestari Mahaputra Buana). Menurut Gary Dessler (2009) faktor - faktor yang mempengaruhi kualitas kerja karyawan antara lain kompensasi, kesejahteraan, hubungan kerja, training, survey opini, penilaian prestasi, jam kerja yang luwes, gugus kendali, dana pengeluaran. Berdasarkan faktor - faktor tersebut dapat dilihat bahwa jam kerja yang luwes dan kesejahteraan menjadi faktor yang paling berpengaruh. Karena jam kerja yang luwes secara langsung mempengaruhi fisik dan mental karyawan yang dapat mengakibatkan kelelahan kerja apabila jam kerja yang diberlakukan oleh perusahaan melebihi batas kemampuan karyawan. Kelelahan kerja (burnout) dapat dilihat dari jumlah ketidakhadiran karyawan yang tinggi. Ketidakhadiran karyawan tersebut terdiri dari karyawan dengan alasan mangkir/ alfa, sakit dan ijin. Karyawan yang merasa kelelahan 
dalam bekerja akan mengalami penurunan mutu kerjanya karena beban kerja yang semakin tinggi sehingga akan berdampak negatif bagi perusahaan. Selain kelelahan kerja (burnout), salah satu faktor lain yang mempengaruhi kinerja karyawan adalah disiplin kerja. Dari hasil pra penelitian yang telah dilakukan pada tanggal 20 Januari 2016, karyawan PT. Lestari Mahaputra Buana memiliki disiplin kerja yang kurang baik. Hal ini dapat dilihat dari kinerja karyawan yang masih kurang maksimal belum sesuai dengan target perusahaan dan fluktuasi absensi karyawan mangkir yang cukup tinggi.

Kedisiplinan merupakan fungsi operasional dari Manajemen Sumber Daya Manusia (MSDM) yang paling penting. Dimana semakin baik tingkat kedisiplinan seorang karyawan maka semakin baik pula kinerja perusahaan yang tercapai. Adapun sebaliknya, tanpa disiplin yang baik, suatu perusahaan akan sulit memperoleh hasil yang optimal, oleh karena itu kedisiplinan merupakan kunci keberhasilan suatu organisasi dalam mencapai tujuannya (Veitzal Rivai, 2011:824).

Berdasarkan pemaparan di atas, dapat dikatakan bahwa penyebab rendahnya kinerja karyawan berkaitan dengan faktor kelelahan kerja (bunrout) dan disiplin kerja karyawan. Sehingga masalah kinerja karyawan perlu diatasi, agar tidak menghambat proses kegiatan operasional perusahaan dalam mencapai tujuan yang telah ditetapkan. Penelitian ini bertujuan untuk memperoleh (1) gambaran kelelahan kerja (burnout). (2) gambaran disiplin kerja pada karyawan. (3) gambaran kinerja pada karyawan. (4) pengaruh kelelahan kerja (burnout) dan disiplin kerja terhadap kinerja karyawan. (5) pengaruh kelelahan kerja (burnout) terhadap kinerja karyawan. (6) pengaruh disiplin kerja terhadap kinerja karyawan.

\section{KAJIAN PUSTAKA}

Anwar Prabu Mangkunegara, (2009:67) mengemukakan "Kinerja adalah hasil kerja secara kualitas dan kuantitas yang dicapai oleh seorang pegawai dalam melaksanakan tugasnya sesuai dengan tanggung jawab yang diberikan kepadanya". Sedarmayanti (2011:260) menyebutkan bahwa yang dimaksud dengan kinerja merupakan terjemahan dari performance yang berarti hasil kerja seorang pekerja, sebuah proses manajemen atau suatu organisasi secara keseluruhan, dimana hasil kerja tersebut harus dapat ditunjukkan buktinya secara konkrit dan dapat diukur.

Gomez-Mejia dan Balkin (2012:225) mengemukakan bahwa dimensi kinerja terdiri dari: 1) Quality of work (Kualitas pekerjaan), 2) Quantity of work performed (Kuantitas pekerjaan yang dilakukan), 3) Interpersonal effectiveness (Efektivitas interpersonal) dan 4) Competence (Kompetensi). Anwar Prabu Mangkunegara (2009:67) menyatakan bahwa "Faktor yang memengaruhi pencapaian kinerja adalah faktor kemampuan (ability) dan faktor motivasi (motivation)".

Freudenberger (1980:74) mendefinisikan (burnout) sebagai : "...A state of fatigue or frustration brought about by devotion to a cause, way of life, or relationship that failed to produce the expected reward." Berdasarkan definisi yang telah dijelaskan sebelumnya bahwa burnout ialah suatu keadaan kelelahan atau frustrasi yang ditimbulkan oleh devosi yang disebabkan oleh cara hidup, atau hubungan yang gagal menghasilkan penghargaan yang diharapkan. Menurut Imelda Novelina Sihotang dalam jurnal Employees' Burnout in Relation to 
Perception toward Psychological Work Environment and Sex (2004:2) tertulis bahwa Burnout mempunyai lima dimensi utama, yaitu kelelahan fisik, kelelahan emosional, kelelahan mental, rendahnya penghargaan terhadap diri dan depersonalisasi

Selain kelelahan kerja (burnout), disiplin kerja karyawan juga diperlukan, karena merupakan suatu alat yang digunakan para manajer untuk berkomunikasi dengan karyawan agar mereka bersedia untuk mengubah suatu perilaku serta sebagai suatu upaya untuk meningkatkan kesadran dan kesediaan seseorang mentaati semua peraturan perusahaan dan norma-norma sosial yang berlaku (Rivai dan Sagala, 2011:824).

Disiplin adalah suatu sikap menghormati, menghargai, patuh, dan taat terhadap peraturan-peraturan yang berlaku, baik yang tertulis maupun tidak tertulis serta sanggup menjalankannya dan tidak mengelak untuk menerima sanksi-sanksinya apabila melanggar tugas dan wewenang yang diberikan kepadanya secara sukarela tanpa adanya paksaan (Siswanto, 2009:291; Hari Mulyadi, 2010). Displin tidak hanya sebatas hukuman, melainkan sebagi arahan dalam memperbaiki sikap karyawan agar patuh dan tunduk pada aturan yang ada. Torrington, Hall, Taylor, \& Atkinson, 2014:394). Adanya aturan disiplin kerja bertujuan untuk membantu karyawan dalam mematuhi peraturan tata tertib suatu organisasi. sehingga tujuan disiplin dapat mengatasi permasalahan produktivitas kerja, keamanan dan keselamatan dalam bekerja serta memperbaiki moral karyawan (Raymond A. Noe, 2011:297).

Kualitas karyawan dapat dilihat dari disiplin kerja yang dilakukan sehari-hari. Dengan memacu disiplin kerja tinggi diharapkan dapat meningkatkan input perusahaan yang mendatangkan profit.
Sehingga disiplin mendorong produktivitas/ disiplin merupakan sarana penting untuk mencapai produktivitasa mencapai kepuasan kerja bagi setiap orang karyawan (Darma Tintri, 2009; Sinungan, 2009:148; Ahim Surachim, 2008). Adapun dimensi disiplin kerja yang digunakan dalam penelitian ini yaitu time (waktu), prohibited behaviour (perilaku terlarang), insurbordination (pembangkangan), illegal behaviour (perialku ilegal), safety (keselamatan) ( John M. Ivancevich 2004:532).

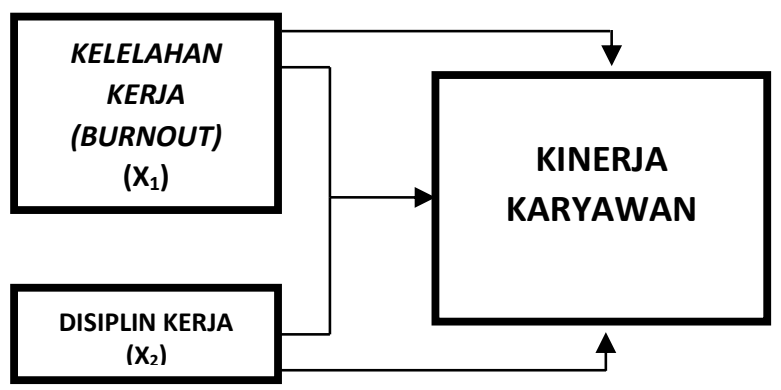

\section{Gambar 1: Paradigman Penelitian}

\section{METODEPENELITIAN}

Penelitian ini dilakukan untuk mengetahui pengaruh kelelahan kerja (burnout) dan disiplin kerja terhadap kinerja karyawan. Adapun yang menjadi variabel bebas dalam penelitian ini adalah kelelahan kerja (burnout) dan disiplin kerja, serta variabel terikatnya adalah kinerja karyawan. Total sampel minimal pada penelitian ini ialah 100 orang. Teknik pengumpulan data dilakukan dengan menyebar angket.

Penelitian ini dilakukan pada kurung waktu kurang dari satu tahun. Jenis penelitian yang digunakan adalah deskriptif, verifikatif. Metode yang digunakan adalah explanatory survey dengan teknik sampel yaitu systematic random sampling menggunakan sampling jenuh yang berjumlah 100 responden. Teknik analisa data yang digunakan adalah regresi liniear berganda dengan alat bantu software 
komputer Statistical Product for Service Solutions (SPSS) 23.0 for windows. Sifat verifikatif pada dasarnya ingin menguji kebenaran dari suatu hipotesis yang dilaksanakan melalui pengumpulan data di lapangan (Lili Adi Wibowo, 2009), maka dalam penelitian ini akan dilakukan pengujian mengenai seberapa besar kelelahan kerja (burnout) dan disiplin kerja terhadap kinerja karyawan.

\section{HASIL DAN PEMBAHASAN}

Pengujian dalam penelitian ini menggunakan Uji $\mathrm{F}$ dengan tujuan untuk mengetahui pengaruh secara simultan variabel-variabel independent, yaitu kelelahan kerja (burnout) dan disiplin kerja terhadap variabel dependent, yaitu kinerja karyawan dengan menggunakan uji keberartian regresi. Hasil pengujian menggunakan uji $F_{\text {hitung }}$ sebesar 90.108 untuk kelelahan kerja (burnout) $\left(\mathrm{X}_{1}\right)$ dan disiplin kerja $\left(\mathrm{X}_{2}\right)$ dengan tingkat signifikansi $0.000 \leq 0.05$ artinya kelelahan kerja (burnout) $\left(\mathrm{X}_{1}\right)$ dan disiplin kerja $\left(\mathrm{X}_{2}\right)$ secara keseluruhan model regresi bisa dipakai untuk memprediksi kinerja karyawan berpola linear. Berdasarkan hasil pengujian Linearitas, maka dapat dikatakan bahwa data yang dihasilkan memenuhi asumsi Linearitas.

Peneliti juga melakukan pengujian pengaruh variabel bebas secara bersama-sama terhadap variabel terikat dengan menggunakan uji $F$ yaitu $F_{\text {hitung }}>F_{\text {tabel. }}$ Maka $F_{\text {tabel }}$ dengan 100 responden yaitu pada $\mathrm{a}=0.05$ adalah sebesar 3.09. Sehingga didapat $F_{\text {hitung }}>F_{\text {tabel }}$ atau 90.108> 3.09, maka $\mathrm{H}_{\mathrm{o}}$ ditolak. Sehingga dapat dikatakan bahwa kelelahan kerja (burnout) dan disiplin kerja berpengaruh bersama-sama (simultan) terhadap kinerja karyawan

Model regresi yang digunakan dalam penelitian ini adalah regresi linier berganda yang bertujuan untuk meramalkan naik turunnya variabel dependent, dengan dua variabel independent sebagai faktor predictor yang dimanipulasi. Persamaan regresi linear berganda antara kelelahan kerja (burnout) dan disiplin kerja terhadap kinerja karyawan, yaitu sebagai berikut:

Kinerja Karyawan $=27.946+0.504$ (Kelelahan Kerja) + 0.374 (Disiplin Kerja)

Berdasarkan persamaan regresi linear berganda di atas, konstanta sebesar 27.946, menyatakan bahwa jika tidak ada kelelahan kerja (burnout) dan disiplin kerja $\left(\mathrm{X}_{1}\right.$ dan $\mathrm{X}_{2}=$ 0) maka kinerja karyawan bernilai 27.946 satu satuan nilai. Koefisien regresi $\mathbf{0 . 5 0 4}$ satu satuan nilai artinya setiap terjadi peningkatan kelelahan kerja (burnout) akan meningkatkan kinerja karyawan sebesar 0.504 satu satuan nilai dan sebaliknya jika terjadi penurunan kinerja karyawan, kelelahan kerja (burnout) akan menurunkan kinerja karyawan sebesar 0.504 satu satuan nilai. Sedangkan koefisien regresi 0.374 satu satuan nilai artinya setiap terjadi peningkatan disiplin kerja akan meningkatkan kinerja karyawan sebesar 0.374 satu satuan nilai dan sebaliknya jika terjadi penurunan kinerja karyawan, disiplin kerja akan menurunkan kinerja karyawan sebesar 0.374 satu satuan nilai.

Untuk mengetahui apakah variabelvariabel independent secara parsial berpengaruh nyata atau tidak terhadap variabel dependent. Berikut di bawah ini hasil pengujian hipotesis mengunakan uji $\mathrm{t}(t$-Test). Dapat diketahui besarnya $t_{\text {hitung }}$ melalui uji-t sebesar 13.270 untuk $\mathrm{X}_{1}$ dan untuk $\mathrm{X}_{2}$ sebesar 5650 , sedangkan besarnya $t_{\text {tabel }}=1.984$, karena nilai $t_{\text {hitung }}>t_{\text {tabel }}$ yakni kelelahan kerja $\left(X_{1}\right)=$ 13.270>1.984 maka dapat disimpulkan Ho ditolak dan Ha diterima. Disiplin kerja $\left(\mathrm{X}_{2}\right)=$ 5650>1.984 maka dapat disimpulkan Ho ditolak dan Ha diterima. Hasil uji-t di atas disimpulkan bahwa hipotesis dalam penelitian 
M. T. S. Gunawan et al.,

ini yaitu Ho ditolak dan Ha diterima, sehingga 1). Terdapat pengaruh positif dari kelelahan kerja (burnout) terhadap kinerja karyawan bagian produksi PT. Lestari Mahaputra Buana (PT.LMB) Padalarang Bandung, 2). Terdapat pengaruh positif dari disiplin kerja terhadap kinerja karyawan bagian produksi PT. Lestari Mahaputra Buana (PT.LMB) Padalarang Bandung. 3). Terdapat pengaruh positif dari kelelahan kerja (burnout) dan disiplin kerja terhadap kinerja karyawan bagian produksi PT. Lestari Mahaputra Buana (PT.LMB) Padalarang Bandung

Berdasarkan hasil penelitian yang bersifat empiris berupa pengaruh kelelaham kerja (burnout) terhadap kinerja karyawan. Kinerja karyawan dipengaruhi secara positif oleh kelelaham kerja (burnout). Menurut Imelda Novelina Sihotang dalam jurnal Employees' Burnout in Relation to Perception toward Psychological Work Environment and Sex (2004), Hubungan negatif antara perpektif terhadap lingkungan kerja psikologis dengan burnout dan ada perbedaan tingkat burnout berdasarkan jenis kelamin karyawan wanita mengalami burnout lebih tinggi dari pria.

Schultz \& Schultz, (1994), Wanita memperlihatkan frekuensi lebih besar untuk mengalami burnout daripada pria, yang disebabkan karena seringnya wanita merasakan kelelahan emosional.

Stephanie M. Mazerolle, PhD, ATC, Kelly D. Pagnotta, MA dalam jurnal Student Perspectives on Burnout (2011), mengemukakan bahwa Faktor pribadi dan organisasi, seperti tingkat stres, jaringan dukungan sosial, waktu pribadi, beban kerja, konflik peran, dan permintaan organisasi, telah didokumentasikan sebagai prediktor kejenuhan bagi penyedia layanan kesehatan. Temuan pada penelitian tersebut ialah ketika ditanya bagaimana mereka didefinisikan kelelahan, para peserta mengidentifikasi kelelahan emosional dan fisik dengan kondisi, dan terkait dengan pengalaman stres berkepanjangan.

Berdasarkan hasil penelitian yang bersifat empiris berupa pengaruh disiplin kerja terhadap kinerja karyawan. Kinerja kerja karyawan dipengaruhi secara positif oleh disiplin kerja. Hal tersebut dibuktikan juga oleh penelitian Henry Simamora (2004:442) yang menjelaskan beberapa faktor yang mempengaruhi kinerja karyawan sebagai berikut, 1). Kurangnya pengetahuan karyawan tentang dasar pekerjaan yang dijalaninya, 2). Tidak adanya kreativitas karyawan untuk mengembangkan pekerjaan, 3). Kurang adanya kerjasama antara pegawai yang lain, 4). Kurang adanya tanggung jawab terhadap perusahaan, 5). Kurang inisiatif dalam bekerja, 5). Faktor kesehatan yang tidak mendukung, misalnya penyakit menahun yang diderita karyawan sehingga tidak dapat bekerja maksimal, 6). Faktor psikologis adanya perbedaan perlakuan karyawan oleh antar karyawan itu sendiri maupun oleh perusahaan, 6). Kurang adanya pengembangan diri karyawan itu sendiri, 7).Lemahnya pendidikan yang dimiliki karyawan.

Dari penjelasan tersebut dapat dikatakan bahwa dengan faktor kesehatan yang tidak mendukung, faktor psikologis yang kurang stabil dan kurangnya tanggung jawab (disiplin) terhadap perusahaan dapat mempengaruhi kinerja karyawan.

Kedisiplinan merupakan fungsi operatif MSDM yang terpenting. Semakin baik disiplin karyawan pada sebuah perusahaan, maka semakin tinggi prestasi kerja yang dapat dicapai. Sebaliknya tanpa disiplin karyawan yang baik, sulit bagi perusahaan mencapai hasil yang optimal. Kekurangdisplinan di dalam manajamen suatu perusahaan juga dapat 
mengakibatkan kerugian bahkan jatuhnya perusahaan itu sendiri, akibat dari sisi karyawan yang banyak melanggar disiplin. (Veithzal Rivai dan Ella J. Sagala, 2011:824).7

\section{KESIMPULAN DAN SARAN}

Berdasarkan uraian teori dan hasil penelitian yang telah dilakukan dengan menggunakan analisis deskriptif dan verifikatif serta uji regresi linier berganda antara lingkungan kerja fisik dan disiplin kerja terhadap produktivitas kerja karyawan bagian produksi PT. Garuda Mas Semesta (Gamatex) Cimahi, dapat ditarik kesimpulan bahwa kelelahan kerja (burnout) berada pada kategori cukup baik, disiplin kerja berada pada kategori cukup tinggi dan kinerja karyawan berada pada kategori tinggi. Hasil uji t menunjukkan bahwa kelelahan kerja (burnout) dan disiplin kerja berpengaruh terhadap kinerja karyawan, dimana kenaikan pada kelelahan kerja (burnout) dan disiplin kerja akan berpengaruh terhadap peningkatan kinerja karyawan. Penelitian ini diharapkan dapat dijadikan sebagai informasi dan dorongan dalam melakukan penelitian selanjutnya mengenai pengaruh kelelahan kerja (burnout) dan disiplin kerja terhadap kinerja karyawan. 


\section{DAFTAR PUSTAKA}

Ahim Surachim. (2008). Pengaruh Iklim Organisasi terhadap Kepuasan Kerja Karyawan pada Divisi Pharmaserve di PT. Combiphar Jakarta. Strategic, 7, 5864.

Anwar Prabu Mangkunegara. 2007. Manajemen Sumber Daya Manusia Perusahaan. Bandung:Remaja Rosdakarya

Ali, Moch. 1985. Penelitian Pendidikan Prosedur dan Strategi. Bandung: Angkasa

Alwi, Syafaruddin. 1989. Alat - Alat Analisis Dalam Pembelanjaan. Andi Offset

Arifin, Nur. 1999. Aplikasi konsep Quality of Worklife (QWL) dan Upaya Menumbuhkan Motivasi Karyawan berkinerja Unggul. Usahawan No. 10 Th. XXVIII.

Ahim Surachim. (2008). Pengaruh Iklim Organisasi terhadap Kepuasan Kerja Karyawan pada Divisi Pharmaserve di PT. Combiphar Jakarta. Strategic, 7, 5864.

Anwar Prabu Mangkunegara. 2007. Manajemen Sumber Daya Manusia Perusahaan. Bandung:Remaja Rosdakarya

Ali, Moch. 1985. Penelitian Pendidikan Prosedur dan Strategi. Bandung: Angkasa

Alwi, Syafaruddin. 1989. Alat - Alat Analisis Dalam Pembelanjaan. Andi Offset
Arifin, Nur. 1999. Aplikasi konsep Quality of Worklife (QWL) dan Upaya Menumbuhkan Motivasi Karyawan berkinerja Unggul. Usahawan No. 10 Th. XXVIII.

Bernardin, H. John and Russel, Joyce. E.A. 2007. Human Resource Management and Productivity. Massachusetts Avenue, Cambridge: National Bureau of Economic Research, Working Paper 16019

Dessler, Gary. 1992. Manajemen Sumber Daya Manusia Jilid I. Indeks.

Flippo, Edwin.B. 2001. Alih bahasa oleh Moh.Masud.Manajemen Personalia edisi ke enam. Jakarta:Erlangga

Gomez-Mejia, Luis R and David B. Balkin and Robert L. Cardy. 2012. Managing Human Resources. Prentice Hall: Pearson Education, Inc.

H. Jhon Bernardin. 2002, Human Resource Management: an Experiential Approach. McGraw - Hill Higher Education.

Herbert Freudenberger and Geraldine Richelson. 1983. Burn Out. Random House.

Husein Umar. 2005. Metode Penelitian Untuk Skripsi dan Tesis Bisnis. PT. Raja Grafindo Persada: Jakarta.

I Made Wirartha. 2006. Pedoman Penulisan Usulan Penelitian, Skripsi, dan Tesis. ANDI.

Imam Wahjono, Sentot.2010.Perilaku Organisasi. Graha Ilmu: Yogyakarta. 
Mangkunegara,

A.A.Anwar

Prabu .2000.Manajemen Sumber Daya Perusahaan.Remaja Rosdakarya.

Moeheriono. 2009, Pengukuran Kinerja Berbasis Kompetensi. Ghalia Indonesia.

Richard S. Lazarus. 2006. Stress and Emotion. Springer Publishing Company Inc.

R. Wayne Mondy, Robert M.Noe. Shane R.Premeaux. 1999. Human Resources Management.Seventh Edition. Prentice hall

Rivai Veithzal. 2004. Manajemen Sumber Daya Manusia Untuk Perusahaan: Dari Teori Ke Praktik. Jakarta: PT. Raja Grafindo Persada

Rivai Veithzal dan Sagala J. Ella. 2009.Manajemen Sumber Daya Manusia untuk Perusahaan; Dari Teori ke Praktik. Jakarta. PT. Rajagrafindo Persada

Schultz, D dan Schultz, S.E. 2010.Psychology and Work Today. ( $\left.9^{\text {th }} \mathrm{ed}\right)$. New Jersey: Pearson Education, Inc

Sedarmayanti 2001. Sumber Daya Manusia dan Produktivitas Kerja. Mandar Maju, Bandung.

Sekaran Uma. 2006.Metodologi Penelitian untuk Bisnis, Edisi 4, Buku 1. Jakarta: Salemba Empat

Simamora Henry. 2004. Manajemen Sumber Daya Manusia. Yogyakarta: STIE YKPN

Singgih Santoso.2000. Latihan SPSS statistik parametric. PT.Elex Media Komputindo: Jakarta.
Siswanto Bejo. 2005. Pengantar Manajemen. Jakarta. Bumi Aksara

Suharsimi Arikunto. 2000. Manajemen Penelitian. CV. Alfabeta: Bandung.

Suharsimi Arikunto. 2010. Prosedur Penelitian: Suatu Pendekatan Praktik (Edisi Revisi 2010). Rineka Cipta.

Suliyanto.2006.Metode Riset Bisnis.CV Alfabeta: Bandung

Sugiyono. 2009. Metode Penelitian Kuantitatif Kualitatif Dan RD Alfabeta: Bandung.

Sugiyono.2010. Penelitian Manajemen Bisnis, CV. Alfabeta: Bandung.

Ulber Silalahi. 2009. Metode Penelitian Sosial. PT. Refika Aditama: Bandung.

Veithzal Rivai. 2004. Manajemen Sumber Daya Manusia Untuk Perusahaan dari teori ke praktek. Jakarta:PT. Raja Grafindo Persada. 